\title{
Effects of substrate temperature on nanostructure and band structure of sputtered $\mathrm{Co} 3 \mathrm{O} 4$ thin films
}

\section{$\operatorname{AUTHOR}(S)$ :}

Yamamoto, Hiroki; Tanaka, Shuhei; Hirao, Kazuyuki

\section{CITATION:}

Yamamoto, Hiroki ...[et al]. Effects of substrate temperature on nanostructure and band structure of sputtered Co304 thin films. JOURNAL OF APPLIED PHYSICS 2003, 93(7): 41584162

ISSUE DATE:

2003-04-01

URL:

http://hdl.handle.net/2433/39705

\section{RIGHT:}

Copyright 2003 American Institute of Physics. This article may be downloaded for personal use only. Any other use requires prior permission of the author and the American Institute of Physics. 


\title{
Effects of substrate temperature on nanostructure and band structure of sputtered $\mathrm{Co}_{3} \mathrm{O}_{4}$ thin films
}

\author{
Hiroki Yamamoto a) and Shuhei Tanaka \\ Nanotechnology Glass Project, New Glass Forum, Tsukuba Research Laboratory, Tsukuba Research \\ Consortium, 9-9, 5-Chome, Tokodai, Tsukuba, Ibaraki, 300-2635, Japan \\ Kazuyuki Hirao \\ Division of Material Chemistry, Graduate School of Engineering, Kyoto University, Yoshida-honmachi, \\ Sakyou-ku, Kyoto, 606-8501, Japan
}

(Received 5 August 2002; accepted 3 January 2003)

\begin{abstract}
Effects of substrate temperature $\left(T_{s}\right)$ on nanostructure and band structure of sputtered $\mathrm{Co}_{3} \mathrm{O}_{4}$ thin films were investigated. The lattice constant of $\mathrm{Co}_{3} \mathrm{O}_{4}$ sputtered at room temperature was longer than the reported bulk $\mathrm{Co}_{3} \mathrm{O}_{4}$ value. It decreased with increasing $T_{s}$ and approached the reported value. Average grain size of the film formed at $T_{s}=918 \mathrm{~K}$ was $13.6 \mathrm{~nm}$ which was twice as big as that of the film obtained at $T_{s}=293 \mathrm{~K}$. Intensities of optical absorption peaks increased with increasing $T_{s}$. Band gaps corresponding to the charge transfer from $\mathrm{Co}^{2+}\left(\pi^{*} e\right)$ to $\mathrm{Co}^{2+}\left(\pi^{*} t_{2}\right)(0.8 \mathrm{eV})$, from $\mathrm{Co}^{3+}\left(\pi^{2} t_{2}\right)$ to $\mathrm{Co}^{2+}\left(\sigma^{*} t_{2}\right)(1.3 \mathrm{eV})$, and from $\mathrm{O}^{2-}\left(\pi^{*} \Gamma\right)$ to $\mathrm{Co}^{2+}\left(\sigma^{*} t_{2}\right)(2.1 \mathrm{eV})$ increased as a function of $T_{s}$. Detailed analysis of the optical absorption spectra in the infrared region indicated that there were many kinds of defects in the $\mathrm{Co}_{3} \mathrm{O}_{4}$ thin film formed at $T_{s}=293 \mathrm{~K}$ and there were fewer defects in the film formed at $T_{s}=918 \mathrm{~K}$. The defects, low density, and increasing interface area at intergrains of nanoparticles caused a lowering of $E_{g}$ at lower substrate temperature. (C) 2003 American Institute of Physics. [DOI: 10.1063/1.1555681]
\end{abstract}

\section{INTRODUCTION}

$\mathrm{Co}_{3} \mathrm{O}_{4}$ thin films have significant optical nonlinearity which is derived from their nanostructure and band structure. ${ }^{1-8}$ To obtain $\mathrm{Co}_{3} \mathrm{O}_{4}$ thin films, the sol-gel, ${ }^{9}$ chemical vapor deposition, ${ }^{10}$ spray pyrolysis, ${ }^{11}$ and sputtering ${ }^{12}$ methods are used. The sputtering method is useful because it is applicable to optical disks, magnetic disks, and other electronic and optical devices. ${ }^{5,13}$ However, it imparts a high energy to the source materials, and as they are quenched on the substrate, the thin film obtained is in a nonequilibrium state. Transition metal oxides like $\mathrm{Co}_{3} \mathrm{O}_{4}$ easily change their valence states, so many kinds of defects will exist in their sputtered thin films.

One of the effective parameters that improves the structure of thin films is substrate temperature $\left(T_{s}\right)$ during sputtering because it changes the quenching conditions of the source materials. In the present study, we focus on the effects of $T_{s}$ on the optical properties, defects, nanostructure, and band structure of $\mathrm{Co}_{3} \mathrm{O}_{4}$ thin films, and we discuss the relationship among these parameters.

\section{EXPERIMENTAL PROCEDURE}

The $\mathrm{Co}_{3} \mathrm{O}_{4}$ films were obtained by rf magnetron sputtering on silica glass substrates. An SPF-750HL sputtering device (Anelva Techno Business Co. Ltd.) was used to form the thin films. The substrate temperature was changed from 293 to 918 K. $99.9999 \%$ argon gas was used as sputtering gas. Sputtering power was $1.0 \mathrm{~kW}$ on a $152.4 \mathrm{~mm} \phi \mathrm{Co}_{3} \mathrm{O}_{4}$ tar-

a)Electronic mail: h-yama@ngp.trc-net.co.jp get. Each film had about $70 \mathrm{~nm}$ thickness. Back pressure was under $4.0 \times 10^{-5} \mathrm{~Pa}$, and the pressure during sputtering was $7.0 \times 10^{-1} \mathrm{~Pa}$.

The lattice constant, $a$ axis of the normal spinel structure of $\mathrm{Co}_{3} \mathrm{O}_{4}$, was measured using wide range x-ray diffraction (XRD, Rigaku RU-200). The nanostructure was evaluated by transmission electron microscopy (TEM), and a Hitachi H-9000NAR was used for those observations. The acceleration voltage was $300 \mathrm{kV}$. The specimens for TEM were prepared with an ion milling device (Gatan Model $600 \mathrm{~N}$ ).

Optical absorption spectra of the films were measured by an optical spectrum analyzer (Hitachi Ltd., U-3500). They were calculated from transmittance and reflectance spectra. Transmittance and reflectance of the substrate were subtracted as the baseline. The detailed structure of the optical absorption spectra in the infrared region was measured using an optical spectrum analyzer (Ando Electric Co. Ltd., AQ6315A) with white light (Ando Electric Co. Ltd., AQ4303B).

\section{RESULTS}

\section{A. Lattice constant and nanostructure of $\mathrm{Co}_{3} \mathrm{O}_{4}$ thin films}

Figure 1 shows the lattice constant $\left(a\right.$ axis) of $\mathrm{Co}_{3} \mathrm{O}_{4}$ thin films calculated from the XRD pattern of the thin films as a function of the substrate temperature in the sputtering process $\left(T_{s}\right)$. The lattice constant decreased with increasing $T_{s}$. According to powder diffraction results, the lattice constant of $\mathrm{Co}_{3} \mathrm{O}_{4}$ was $0.808 \mathrm{~nm} .{ }^{9}$ Therefore the lattice constant of $\mathrm{Co}_{3} \mathrm{O}_{4}$ film formed at lower $T_{s}$ was larger, and it approached the reported value as $T_{s}$ was increased. 


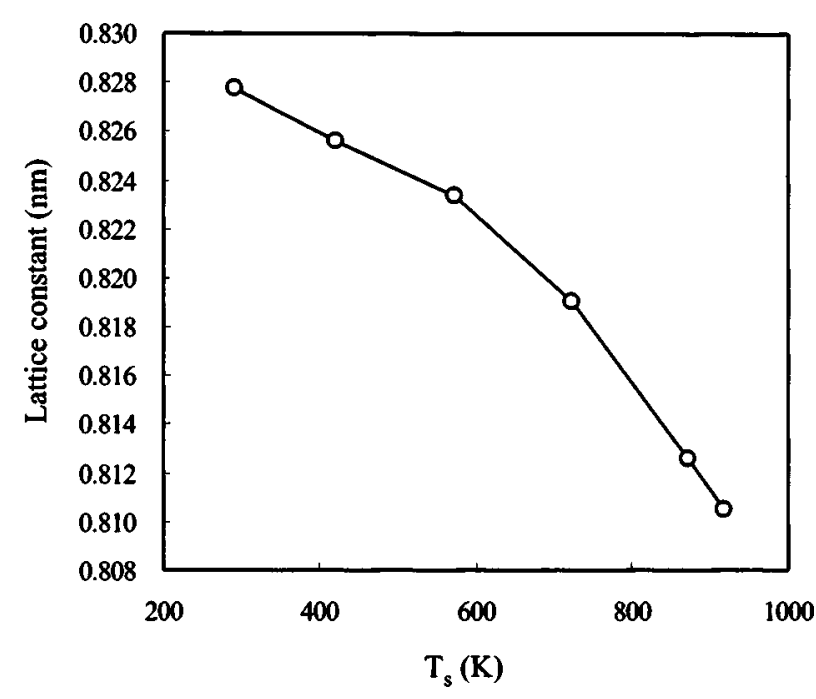

FIG. 1. Lattice constant of $\mathrm{Co}_{3} \mathrm{O}_{4}$ thin films as a function of substrate temperatures $\left(T_{s}\right)$.

Figure 2 shows the intensity of peaks 111, 311, and 511 and their summation as a function of $T_{s}$. From 273 to $593 \mathrm{~K}$, there were no significant changes in the intensity of the peaks. Peak 111 increased dramatically in the $T_{s}$ region from 723 to 918 K. Peaks 311 and 511 increased from 723 to 873 $\mathrm{K}$. The summation of the intensity of these peaks also increased, indicating the improved crystallinity or grain growth obtained by increasing $T_{s}$.

In the lower $T_{s}$ region under $423 \mathrm{~K}$, peak 311 was dominant indicating that the $\mathrm{Co}_{3} \mathrm{O}_{4}$ thin films had a random orientation because peak 311 is the highest in the powder diffraction pattern of $\mathrm{Co}_{3} \mathrm{O}_{4} \cdot{ }^{9}$ On the other hand, peak 111 was the highest in higher $T_{s}$ regions above $573 \mathrm{~K}$, showing that the $\mathrm{Co}_{3} \mathrm{O}_{4}$ films had a 111 orientation tendency.

Figure 3 shows the high resolution TEM image of the $\mathrm{Co}_{3} \mathrm{O}_{4}$ thin films formed at (a) $T_{s}=293 \mathrm{~K}$ and (b) $918 \mathrm{~K}$. Both films consisted of nanoscale particles, and the lattice image indicated that these particles were $\mathrm{Co}_{3} \mathrm{O}_{4}$. The grain size of $\mathrm{Co}_{3} \mathrm{O}_{4}$ thin films obtained at $918 \mathrm{~K}$ of $T_{s}$ was almost

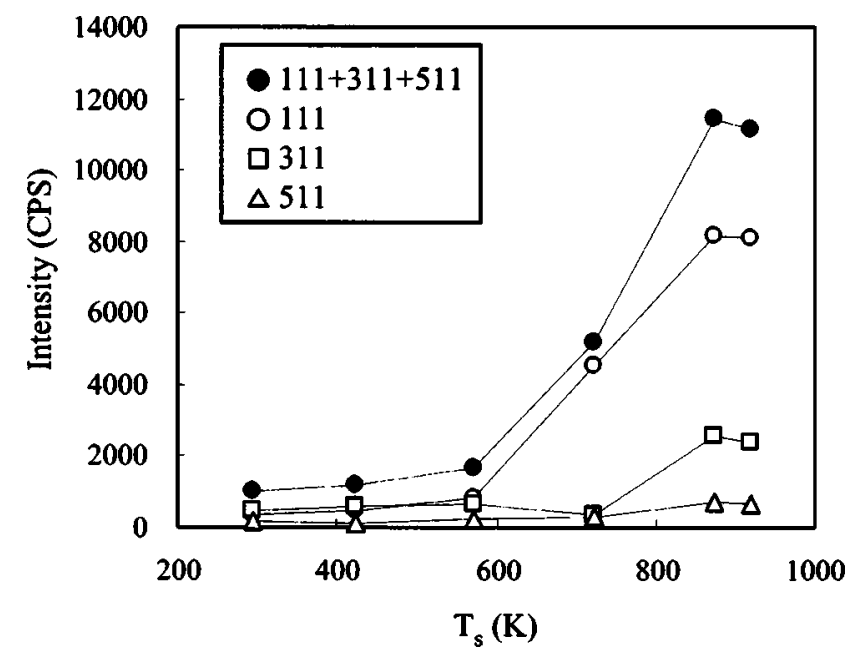

FIG. 2. Peak intensities of x-ray diffraction patterns of $\mathrm{Co}_{3} \mathrm{O}_{4}$ thin films obtained at several substrate temperatures.
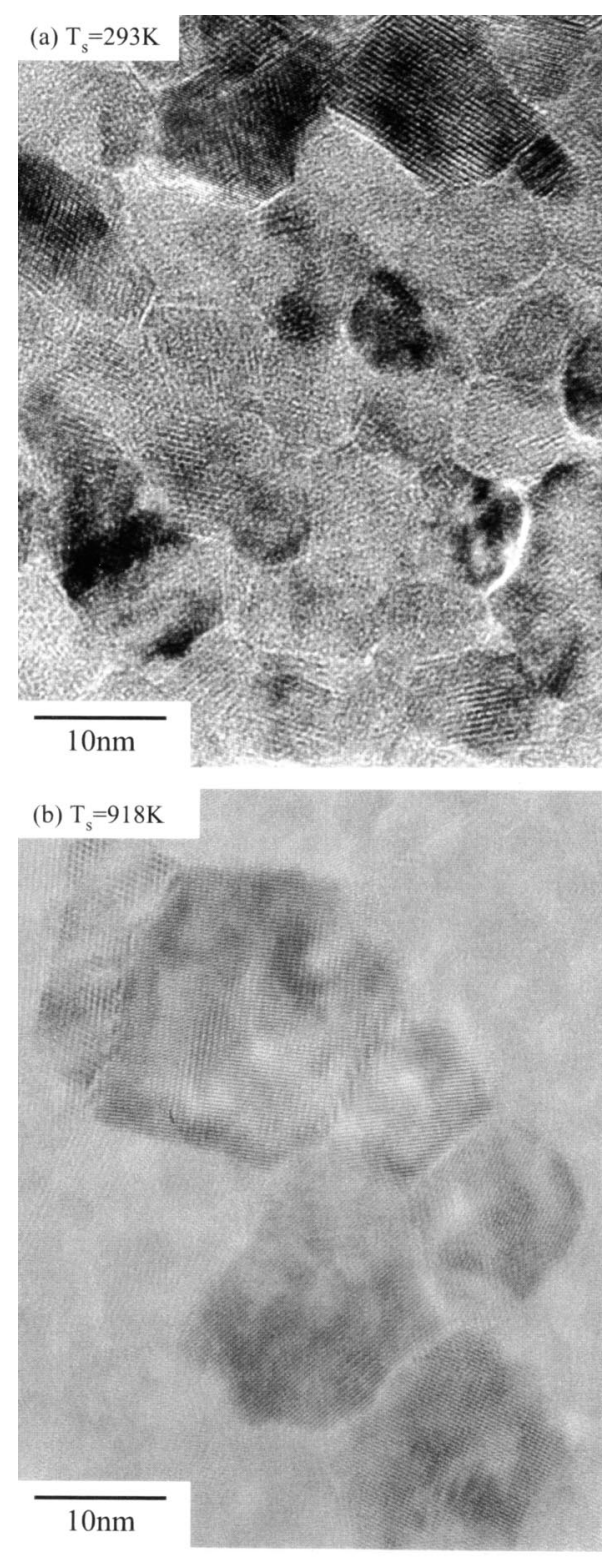

FIG. 3. Transmittance electron micrographs of the $\mathrm{Co}_{3} \mathrm{O}_{4}$ thin films obtained at $T_{s}$ of (a) $293 \mathrm{~K}$ and (b) $918 \mathrm{~K}$.

twice as big as that of the films obtained at $293 \mathrm{~K}$. A grain boundary phase, $1.0 \mathrm{~nm}$ thick, could be observed in both films.

To investigate the grain size in detail, we calculated the grain size dispersion. Figure 4 shows the dispersion of the grain size of the $\mathrm{Co}_{3} \mathrm{O}_{4}$ thin films obtained at $T_{s}=293$ and $918 \mathrm{~K}$ calculated from the film TEM images. The average grain size (d) of $\mathrm{Co}_{3} \mathrm{O}_{4}$ thin film formed at $293 \mathrm{~K}$ was 7.40 $\mathrm{nm}$ and the standard deviation of the grain size $(\sigma)$ was 1.69 $\mathrm{nm}$. The $d$ and $\sigma$ of $\mathrm{Co}_{3} \mathrm{O}_{4}$ film formed at $918 \mathrm{~K}$ were 13.6 and $3.63 \mathrm{~nm}$, respectively. Therefore $d$ and $\sigma$ of $\mathrm{Co}_{3} \mathrm{O}_{4}$ film formed at $918 \mathrm{~K}$ were almost twice and eight times, respectively, as big as those of the $\mathrm{Co}_{3} \mathrm{O}_{4}$ thin film formed at 293 $\mathrm{K}$. The grain growth at higher substrate temperatures is one cause of the increased total intensity of the XRD pattern seen in Fig. 2. 


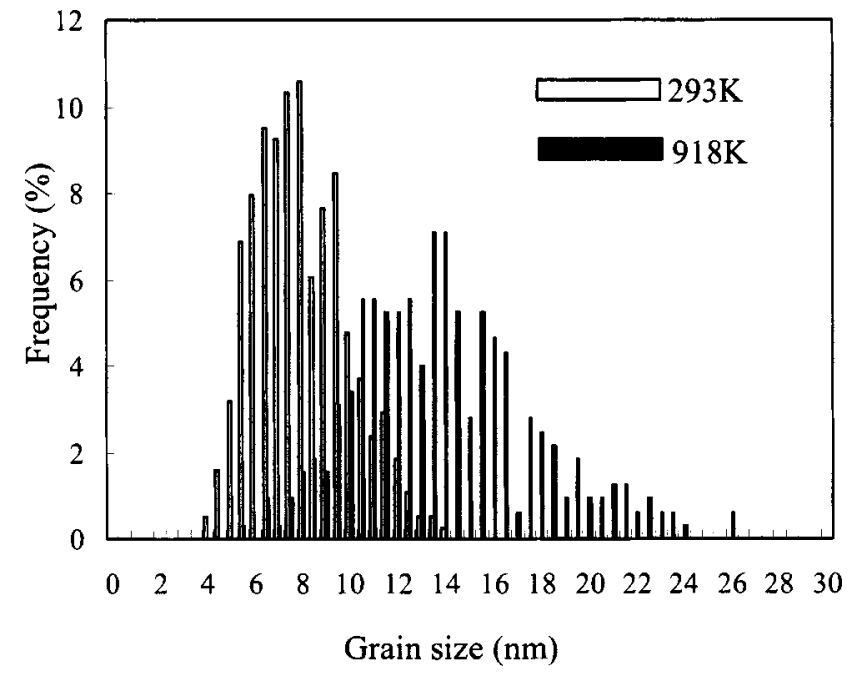

FIG. 4. Grain size dispersion of the $\mathrm{Co}_{3} \mathrm{O}_{4}$ thin films formed at $T_{s}$ of 293 and $918 \mathrm{~K}$.

\section{B. Optical absorption spectra and band gap energy estimation}

Figure 5 shows the optical absorption spectra of $\mathrm{Co}_{3} \mathrm{O}_{4}$ thin films formed at several substrate temperatures. $\mathrm{Co}_{3} \mathrm{O}_{4}$ films had some absorption peaks at $0.75,0.9,1.7$, and $3.0 \mathrm{eV}$. The intensities of all absorption peaks increased with increasing $T_{s}$. Figure 6 shows the detailed optical absorption spectra of the $\mathrm{Co}_{3} \mathrm{O}_{4}$ thin films obtained at $T_{s}=293$ and 918 $\mathrm{K}$ in the wavelength region from 0.75 to $1.25 \mathrm{eV}$. A lot of small absorption peaks were observed in the spectrum of the sample formed at $T_{s}=293 \mathrm{~K}$. Such small absorption peaks, which looked like the noise signals of the thin films formed at room temperature, were reproducible. The small peaks in the near infrared region were due to defects including interface area at intergrains of nano particles in the $\mathrm{Co}_{3} \mathrm{O}_{4}$ crystals. On the other hand, there was a broad peak corresponding to 0.75 and $0.9 \mathrm{eV}$ of absorption peaks in the spectrum of the sample obtained at $T_{s}=918 \mathrm{~K}$ instead of the small absorption peaks. Therefore the defects in the film formed at higher $T_{s}$ were fewer in number than for the film formed at

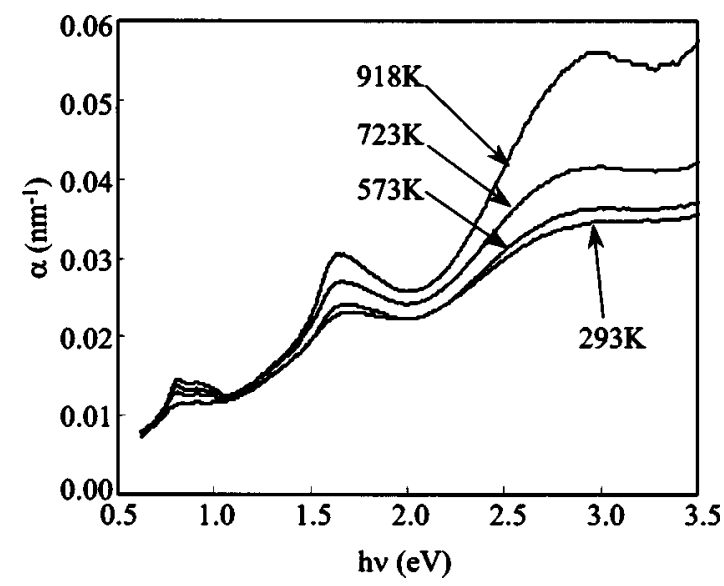

FIG. 5. Optical absorption spectra of $\mathrm{Co}_{3} \mathrm{O}_{4}$ thin films formed at $T_{s}$ of 293, 573, 723, and $918 \mathrm{~K}$.

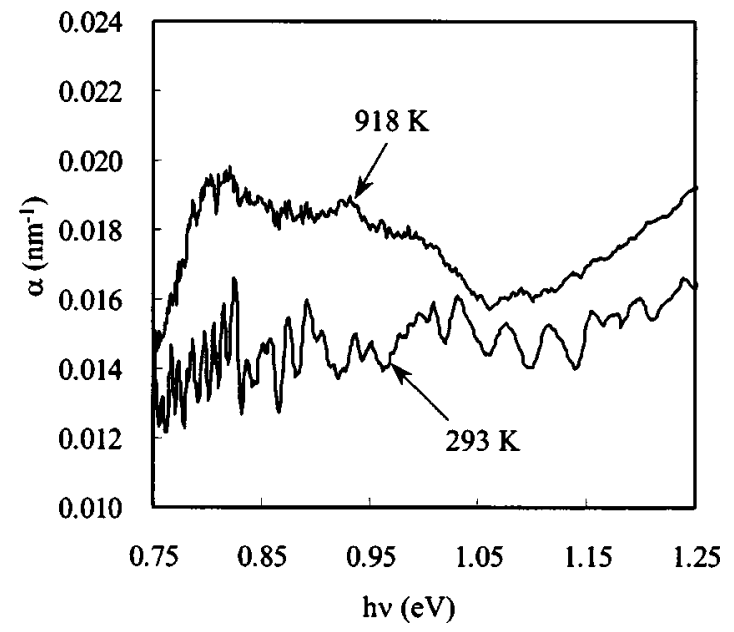

FIG. 6. Detailed measurements of the optical absorption spectra of the $\mathrm{Co}_{3} \mathrm{O}_{4}$ thin films obtained at $293 \mathrm{~K}$ and $918 \mathrm{~K}$ in the near infrared region.

lower $T_{s}$, and absorption peaks due to the $\mathrm{Co}_{3} \mathrm{O}_{4}$ structure that was defect-free appeared in the sample formed at higher $T_{s}$.

To investigate the details of the band structure of these films, we estimated the allowed direct transition energy using the formula ${ }^{11}$

$$
\alpha=\alpha_{0} \frac{\left(h \nu-E_{g}\right)^{n}}{h \nu} .
$$

Here $\alpha$ is an absorption coefficient, $\alpha_{0}$ is a constant, and $h \nu$ is the photon energy. In the allowed direct transition, $n=\frac{1}{2}$. Hence

$$
(a h \nu)^{2}=\alpha_{0}^{2}\left(h \nu-E_{g}\right),
$$

if

$$
\alpha h \nu \rightarrow 0, \quad h \nu=E_{g} .
$$

Therefore extrapolation of the straight line portion to zero absorption coefficient in the $(\alpha h \nu)^{2}$ versus $h \nu$ curves gives band gap energy $E_{g}$.

Figure 7 plots $(\alpha h \nu)^{2}$ versus photon energy. Patil et al. ${ }^{11}$ showed that there are two energy levels of the direct allowed transition at 2.0 and $1.3 \mathrm{eV}$ in the $\mathrm{Co}_{3} \mathrm{O}_{4}$ thin films. We found that other band gaps were present at lower photon energies, about 0.7 and $1.0 \mathrm{eV}$. These two peaks were overlapped, so we could not decide an accurate value for the band gap of $1.0 \mathrm{eV}$, although we found $E_{g}$ of $0.7 \mathrm{eV}$. The slope of the tangential line for each band gap was less, and the band gaps shifted to lower energy with increasing substrate temperature.

It has been reported that $\mathrm{Co}_{3} \mathrm{O}_{4}$ has band gaps at 0.8 , $1.0,1.3$, and $2.1 \mathrm{eV}$, and $E_{g}$ at $0.8,1.3$, and $2.1 \mathrm{eV}$ are assigned as charge transfers from $\mathrm{Co}^{2+}\left(\pi^{*} e\right)$ to $\mathrm{Co}^{2+}\left(\pi^{*} t_{2}\right)$, from $\mathrm{Co}^{3+}\left(\pi^{2} t_{2}\right)$ to $\mathrm{Co}^{2+}\left(\sigma^{*} t_{2}\right)$, and from $\mathrm{O}^{2-}\left(\pi^{*} \Gamma\right)$ to $\mathrm{Co}^{2+}\left(\sigma^{*} t_{2}\right)$, respectively. ${ }^{14-17}$ We considered that the reported $0.8 \mathrm{eV}$ corresponded to the $0.7 \mathrm{eV}$ value observed in the present study. The calculated $E_{g}$ 's around $0.7,1.3$, and $2.1 \mathrm{eV}$, which could be given accurately from Fig. 7, are plotted as a function of $T_{s}$ in Fig. 8. Every $E_{g}$ value increased as a function of $T_{s}$. 

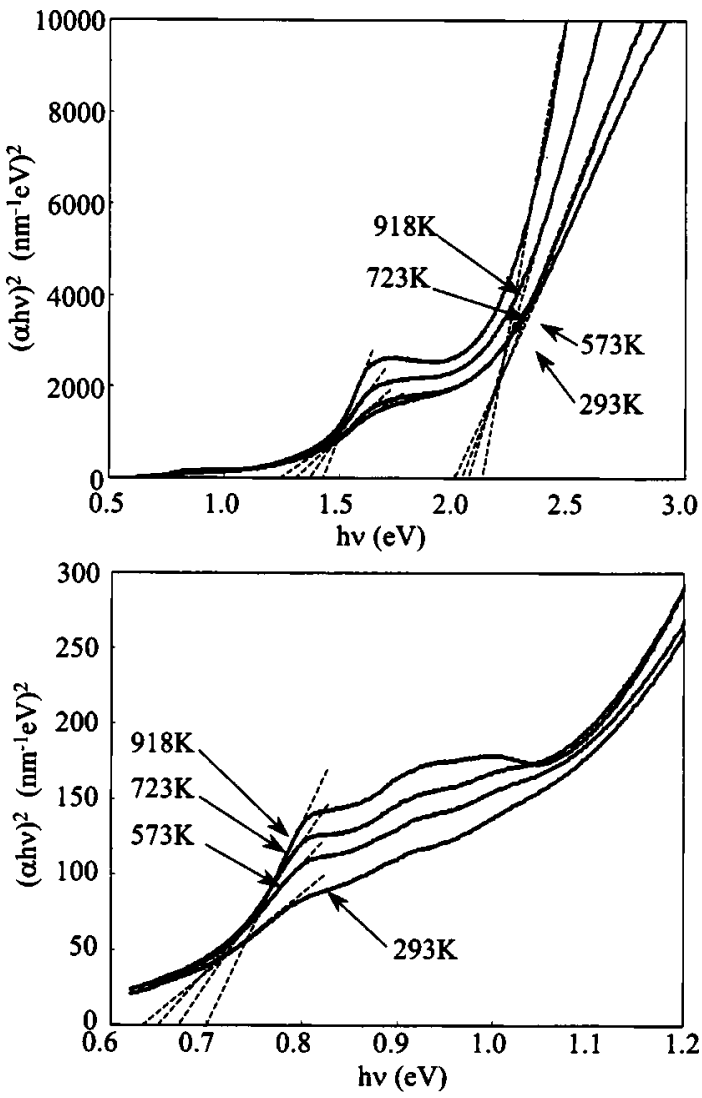

FIG. 7. $(\alpha h \nu)^{2}$ vs photon energy $(h \nu)$ for several substrate temperatures $\left(T_{s}\right)$.

\section{DISCUSSION}

In this section, we consider the relation among the nanostructure, defects, and band structure of the sputtered $\mathrm{Co}_{3} \mathrm{O}_{4}$ thin films and discuss the effects of the substrate temperature on them.

The lattice constant of the $\mathrm{Co}_{3} \mathrm{O}_{4}$ films obtained at lower $T_{s}$ is large, and it approaches the reported value with increasing $T_{s}$. This indicates that densification of the $\mathrm{Co}_{3} \mathrm{O}_{4}$ films progresses with increasing $T_{s}$. Peak intensities of XRD and TEM images show that a higher $T_{s}$ leads to larger grain size of the $\mathrm{Co}_{3} \mathrm{O}_{4}$ particles, and the grain size of the $\mathrm{Co}_{3} \mathrm{O}_{4}$ film formed at $918 \mathrm{~K}$ of $T_{s}$ is almost twice as big as that of the film formed at $293 \mathrm{~K}$ of $T_{s}$. The total XRD peak intensity of the film formed at $T_{s}=918 \mathrm{~K}$ is ten times as large as that formed at $293 \mathrm{~K}$ of $T_{s}$, which is caused by the densification and grain growth of the $\mathrm{Co}_{3} \mathrm{O}_{4}$ films on increasing $T_{s}$. The grain growth causes the interface area at intergrains to decrease. Figure 6 indicates that many kinds of defects exist in the $\mathrm{Co}_{3} \mathrm{O}_{4}$ film formed at $293 \mathrm{~K}$, and the one formed at 918 $\mathrm{K}$ has fewer defects. Therefore increasing $T_{s}$ causes densification, grain growth, and fewer defects of the $\mathrm{Co}_{3} \mathrm{O}_{4}$ thin films.

According to $E_{g}$ analysis, a blueshift of the band gap is observed with increasing $T_{s}$. To consider the relationship between the structure of $\mathrm{Co}_{3} \mathrm{O}_{4}$ films and band gap energy $E_{g}$ we consider the band structure of the $\mathrm{Co}_{3} \mathrm{O}_{4}$ films at high and low substrate temperatures. Figure 9 shows a schematic diagram of the energy bands of $\mathrm{Co}_{3} \mathrm{O}_{4}$ formed at (a) $918 \mathrm{~K}$
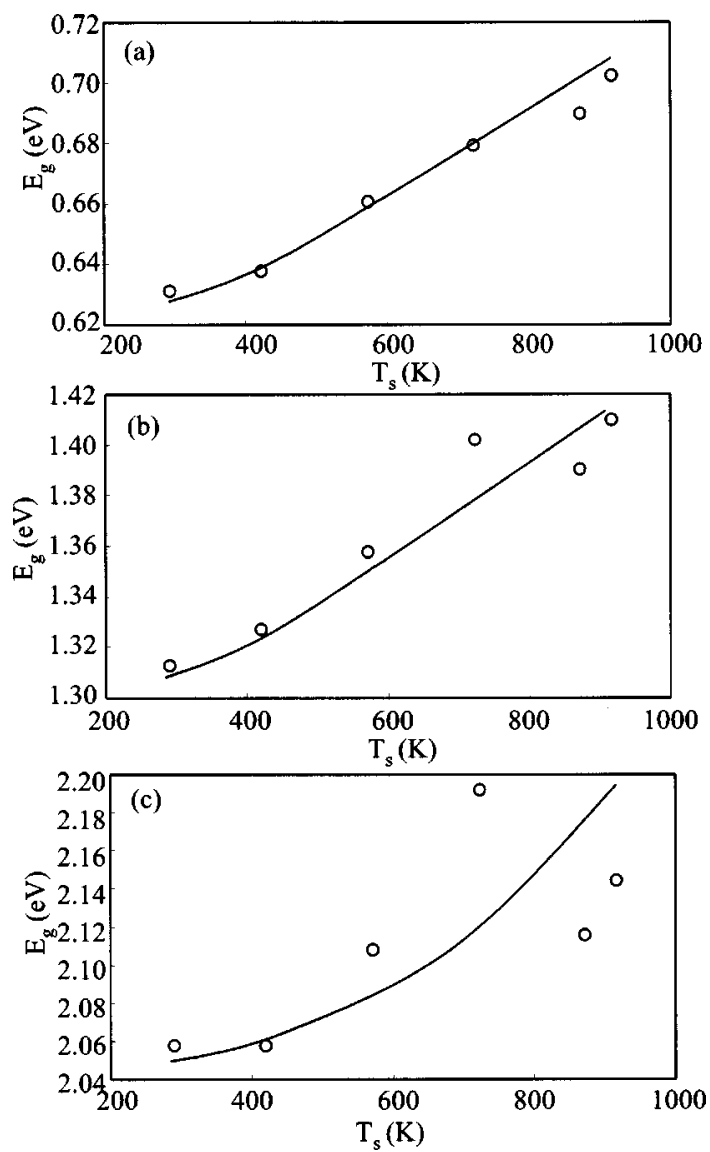

FIG. 8. Band gap shift of $\mathrm{Co}_{3} \mathrm{O}_{4}$ thin films as a function of substrate temperatures $\left(T_{s}\right)$, (a) $E_{g}=1.30 \mathrm{eV}$ and (b) $E_{g}=2.06 \mathrm{eV}$.

and (b) $273 \mathrm{~K}$ of $T_{s}$. The film obtained at $T_{s}=918 \mathrm{~K}$ has fewer defects, a smaller interface at intergrains because of grain growth, and dense crystals like bulk $\mathrm{Co}_{3} \mathrm{O}_{4}$, so that the energy level of the bands has high uniformity in all the films. Therefore, $E_{g}$ is close to constant, and the absorption peak is consequently higher and sharper. On the other hand, as shown in Fig. 9(b), the bands in the $\mathrm{Co}_{3} \mathrm{O}_{4}$ thin films have many defects, a lot of interfaces, and a lower density, so that there are many defects and interface levels and splitting of the bands into several energy levels occurs. Therefore many kinds of transition conditions near the band gap energy oc-

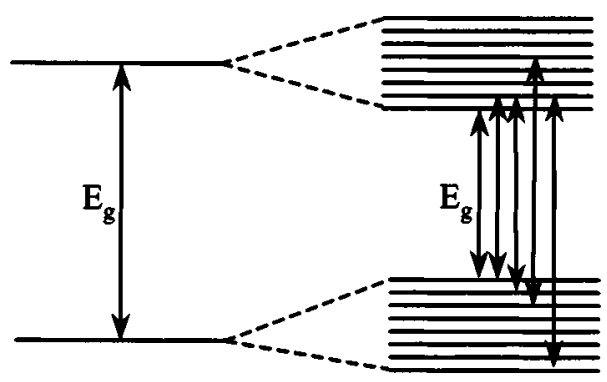

(a)

(b)

FIG. 9. Schematic diagram of the band structure of $\mathrm{Co}_{3} \mathrm{O}_{4}$ thin films obtained at (a) $918 \mathrm{~K}$ and (b) $273 \mathrm{~K}$. 
cur. Simultaneously, the redshift of the minimum band gap energy is also observed. Consequently the broadening and the redshift of the band gap energy observed in the thin films are formed at lower $T_{s}$.

Next, we discuss the effects of $T_{s}$ on the structure of $\mathrm{Co}_{3} \mathrm{O}_{4}$ thin films thermodynamically. In the sputtering process, the migration speed of the source materials on the substrate determines the structure of the thin films. At high substrate temperatures $\left(918 \mathrm{~K}\right.$ in the case of $\left.\mathrm{Co}_{3} \mathrm{O}_{4}\right)$, the migration speed of the atoms or ions is fast because they have high energies on the hot substrate. Therefore the grain growth speed is higher than the nucleation speed and the grain growth is dominant at high temperatures. Consequently, the grain size of the film formed at $918 \mathrm{~K}$ is bigger than that of the film formed at $273 \mathrm{~K}$. The source materials have efficient energy to migrate, so epitaxial grain growth occurs easily. Therefore fewer defects occur in the film obtained at high temperatures.

At high substrate temperatures, it is also easy to overcome the energy barrier to form the 111 orientation of the spinel structure, in which the close-packed surface of the oxygen atoms faces parallel to the substrate surface. Therefore the 111 orientation found at high temperatures is as shown in Fig. 2. However, the relation between the orientation and the blueshift of the band gap energy of $\mathrm{Co}_{3} \mathrm{O}_{4}$ thin films is not clear from this study.

\section{CONCLUSIONS}

We obtained the following results on the effects of substrate temperature $\left(T_{s}\right)$ in the sputtering process on nanostructure and band structure of $\mathrm{Co}_{3} \mathrm{O}_{4}$ thin films. According to our investigation on the lattice constant of sputtered $\mathrm{Co}_{3} \mathrm{O}_{4}$ thin films, the densification progressed at high substrate temperatures, and it approached the reported value of the bulk $\mathrm{Co}_{3} \mathrm{O}_{4}$. Also, TEM observations indicated that grain growth occurred simultaneously. Optical absorption spectra showed that defects in the $\mathrm{Co}_{3} \mathrm{O}_{4}$ thin film decreased at high substrate temperatures. Band gaps corresponding to the charge transfer from $\mathrm{Co}^{2+}\left(\pi^{*} e\right)$ to $\mathrm{Co}^{2+}\left(\pi^{*} t_{2}\right)(0.8 \mathrm{eV})$, from $\mathrm{Co}^{3+}\left(\pi^{2} t_{2}\right)$ to $\mathrm{Co}^{2+}\left(\sigma^{*} t_{2}\right)(1.3 \mathrm{eV})$, and from $\mathrm{O}^{2-}\left(\pi^{*} \Gamma\right)$ to $\mathrm{Co}^{2+}\left(\sigma^{*} t_{2}\right)(2.1 \mathrm{eV})$ increased with increasing $T_{s}$. The defects, low density, and increasing interface area at intergrains of nanoparticles caused a lowering of $E_{g}$ at low substrate temperatures.

\section{ACKNOWLEDGMENT}

This work was carried out in the Nanotechnology Glass Project as part of the Nanotechnology Materials Program supported by the New Energy and Industrial Technology Development Organization (NEDO).

${ }^{1}$ M. Ando, K. Kadono, M. Haruta, T. Sakaguchi, and M. Miya, Nature (London) 374, 625 (1995).

${ }^{2}$ T. Shintani, K. Moritani, A. Hirotsune, M. Terao, H. Yamamoto, and T. Naito, Joint MORIS/ISOM '97 Post-deadline Papers Technical Digest (1997), p. 23.

${ }^{3}$ T. Shintani and M. Terao, Opt. Alliance 9, 10 (1998) (in Japanese).

${ }^{4}$ H. Yamamoto, T. Naito, M. Terao, and T. Shintani, Digest of 11th Fall Meeting of Ceramic Society of Japan (1998), p. 243.

${ }^{5}$ T. Shintani, M. Terao, H. Yamamoto, and T. Naito, Jpn. J. Appl. Phys., Part 1 38, 1656 (1999).

${ }^{6}$ H. Yamamoto, T. Naito, and K. Hirao, Mater. Res. Soc. Symp. Proc. 703, V13.20.1 (2002)

${ }^{7}$ H. Yamamoto, T. Naito, M. Terao, and T. Shintani, Thin Solid Films 411, 289 (2002).

${ }^{8}$ H. Yamamoto, S. Tanaka, T. Naito, and K. Hirao, Appl. Phys. Lett. 81, 999 (2002)

${ }^{9}$ F. Svegl, B. Orel, M. G. Hutchins, and K. Kalcher, J. Electrochem. Soc. 143, 1532 (1996)

${ }^{10}$ T. Maruyama and S. Arai, J. Electrochem. Soc. 143, 1383 (1996).

${ }^{11}$ P. S. Patil, L. D. Kadam, and C. D. Lokhande, Thin Solid Films 272, 29 (1996).

${ }^{12}$ W. Estrada, M. C. A. Fantini, S. C. de Castro, C. N. Polo da Fonseca, and A. Gorenstein, J. Appl. Phys. 74, 5835 (1993).

${ }^{13}$ X. Song, J. Sivertsen, and J. Judy, J. Appl. Phys. 81, 4387 (1997).

${ }^{14}$ J. G. Cook, M. P. van der Meer, and D. Hogg, J. Vac. Sci. Technol. A 4, 607 (1986).

${ }^{15}$ J. G. Cook and M. P. van der Meer, Thin Solid Films 144, 165 (1986).

${ }^{16}$ K. M. E. Miedzinska, B. R. Hollebone, and J. Ǵ. Cook, J. Phys. Chem. Solids 48, 649 (1987).

${ }^{17}$ M. Lenglet and C. K. Jorgensen, Chem. Phys. Lett. 229, 616 (1994). 